\title{
Penentuan Batas Operasi Baru Untuk Sumur Gas di Lapangan Anggrek
}

\author{
Osaliana Budiarto ${ }^{1}$, Iwan Setya Budi ${ }^{2}$ \\ Universitas Pertamina, Jakarta Selatan \\ Universitas Pertamina, Jakarta Selatan
}

\begin{abstract}
AbstraK
Penelitian berfokus pada penerapan batasan operasi baru untuk sumur gas pada Lapangan Anggrek. Lapangan Anggrek menerapkan rekomendasi API-RP-14E sebagai acuan dalam operasi sumur. Metodologi baru mempertimbangkan laju alir minimum, maksimum, dan mempertimbangkan instrumen sumur. Laju alir minimum dievaluasi menggunakan kecepatan minimum untuk menghindari terjadinya penimbunan fluida di dalam sumur. Penimbunan fluida adalah masalah krusial untuk sumur gas. Akumulasi cairan akan menyebabkan kehilangan tekanan yang lebih tinggi di dalam lubang sumur, dan mengurangi performa sumur. Batas laju maksimum sumur gas dievaluasi dengan mempertimbangan resiko erosi. Kerusakan tubing akibat erosi dapat disebabkan oleh aliran gas berkecepatan tinggi. Studi ini membahas operasi optimum di sumur gas dengan memodelkan tipe aliran untuk berbagai ukuran sumur dan parameter produksi harian. Memahami aliran di dalam lubang sumur akan membantu untuk mengetahui fenomena aliran dan memprediksi akumulasi cairan di masa mendatang. Pemilihan ukuran tubing dan penentuan parameter operasi gas harian sangat penting untuk mengantisipasi akumulasi cairan di awal produksi. Dengan menggunakan data lapangan, peneliti melakukan prediksi performa sumur hingga 9 tahun produksi, yaitu awal, tengah dan akhir. Peneliti melihat bahwa sumur dengan ukuran diameter yang lebih besar memiliki recovery factor yang lebih tinggi tetapi life time pendek. Tekanan kepala sumur dan bukaan choke harus dipertahankan untuk menghindari perubahan tipe aliran di dalam sumur. Selain itu, ditemukan bahwa penerapan API-RP-14E terlalu pesimis pada Lapangan Anggrek. Studi ini menawarkan rekomendasi operasi sumur untuk empat ukuran tubing dan menentukan range batas
\end{abstract} operasi sumur yang baru.

Kata kunci: laju alir, akumulasi cairan, produksi

\section{Pendahuluan}

Lapangan Anggrek merupakan reservoir gas. Lapangan ini dibagi menjadi 3 daerah produksi, yaitu Barat, Timur dan Selatan. Bagian selatan merupakan salah satu potensi yang sedang dikembangkan. Cadangan yang terhitung di selatan Anggrek adalah 45Bscf. Cadangan ini akan ditembus oleh 1 sumur dengan masa produksi hingga 9 tahun ke depan. Lapangan ini menerapkan rekomendasi API-RP-14E dalam penentuan batas maksimum laju alir. Namun belum 
ada acuan dalam penetapan minimum laju alir, meskipun pada kenyataannya masalah liquid loading sering terjadi pada beberapa sumur tua di Lapangan Anggrek.

Liquid loading adalah masalah krusial untuk sumur gas. Liquid loading dalam sumur gas adalah suatu akumulasi cairan dalam sumur gas akibat dari penurunan kecepatan gas sehingga fasa gas tidak mampu mentransportasikan liquid ke permukaan dan menimbulkan back pressure ke formasi. Liquid loading sangat berpengaruh terhadap produksi sumur gas hingga dapat mematikan sumur (Febri, dkk, 2017). Salah satu alasan penyebab liquid loading adalah tekanan reservoir yang menurun.

Tekanan reservoir sangat berpengaruh dalam melihat well deliverability dan penentuan laju alir yang optimal. Secara operasional, laju alir dapat diatur dengan memberikan batasan sehingga sumur gas mengalami penurunan tekanan yang bisa ditolerir. Batasan tersebut akan mengurangi kemungkinan liquid loading atau memperlambat fenomena tersebut agar tidak terjadi di early production.

Penelitian ini berfokus pada penerapan Well Operating Limit untuk pengembangan bagian selatan lapangan Anggrek. Metodologi yang digunakan mempertimbangkan laju alir minimum, kecepatan maksimum, dan menggabungkan analisis ukuran tubing. Kriteria laju alur minimum dinilai dengan perhitungan kecepatan minimum untuk menghindari liquid loading. Laju alir maksimum sumur gas akan memperhitungkan kemungkinan erosi.

Peneliti melakukan prediksi produksi pada Sumur Alpha di Lapangan Anggrek hingga 9 tahun produksi. Prediksi dilakukan untuk 4 ukuran tubing yang berbeda. Perbedaan ukuran tubing menghasilkan kriteria laju alir minimum dan maksimum yang beragam. Dalam penelitian ini, peneliti memberikan rekomendasi batas operasi sumur yang baru pada 4 macam ukuran tubing. Alternatif tersebut dapat digunakan sebagai panduan rentang operasi sumur agar dapat menghasilkan recovery factor yang optimum dan mempertimbangkan kemudahan operasi.

\section{Tinjauan Pustaka}

\section{A. Fenomena Liquid loading}

Liquid loading adalah suatu akumulasi cairan dalam sumur gas akibat dari penurunan kecepatan gas. Hal ini menyebabkan gas tidak mampu mengangkat liquid ke permukaan serta menimbulkan back pressure ke formasi. Akumulasi cairan berpotensi menurunkan produksi dan mematikan sumur. Berikut ini merupakan proses yang menyebabkan terjadinya liquid loading (Pratiwi, 2019):

1. Ketika awal sumur berproduksi, sumur masih memiliki tekanan reservoir dan laju alir yang tinggi. Kecepatan gas masih lebih besar dari pada kecepatan kritis yang dibutuhkan untuk mengangkat liquid. Pada fase ini, gas dapat mengangkat liquid ke permukaan.

2. Setelah beberapa waktu sumur berproduksi, tekanan reservoir akan berkurang sehingga adanya penurunan laju alir. Penurunan laju alir juga berdampak pada kecepatan gas. Apabila kecepatan gas mencapai di bawah kecepatan kritis, maka liquid tidak dapat terangkat ke permukaan. Hal ini mengganggu proses produksi dan membuat penurunan laju produksi.

3. Akumulasi cairan di dasar sumur yang mulai terbentuk akan menurunkan flow area untuk 
fas gas yang akan mengakibatkan pressure drop lebih besar. Pressure drop akan terus bertambah dan menimbulkan back pressure sampai mendapatkan tekanan yang diperlukan untuk mengangkat akumulasi cairan tersebut ke permukaan.

4. Akumulasi cairan di dasar sumur seiring dengan berjalannya waktu akan membuat kolom liquid tinggi, sehingga back pressure terus bertambah sehingga sumur akan mengalami kematian.

\section{B. Rekomendasi API-RP-14E}

API RP 14E memperhitungkan kecepatan erosi, kecepatan minimum, dan penurunan tekanan sebagai kriteria untuk laju alir gas. API RP 14E merekomendasikan bila tidak ada yang spesifik informasi mengenai sifat erosif atau korosif dari fluida tersedia, kecepatan aliran multifasa seharusnya dipertahankan di bawah "kecepatan erosi" yang diperoleh dari persamaan empiris berikut:

$$
V_{e}=\frac{c}{\sqrt{\rho_{m}}}
$$

Dimana

Ve : fluid erosional velocity $(\mathrm{ft} / \mathrm{s})$

c : konstanta empiris

$\rho \mathrm{m}$ : densitas campuran pada $\mathrm{P}$ dan $\mathrm{T},\left(\mathrm{lb} / \mathrm{ft}^{3}\right)$

Sani, dkk (2019) menyebutkan ada beberapa limitasi pada API-RP-14E, salah satunya adalah persamaan tersebut hanya memperhitungkan densitas fluida dalam menghitung kecepatan erosi. Sedangkan faktor lain seperti seperti bahan pipa, sifat fluida, geometri aliran dan rezim aliran belum dipertimbangkan.

\section{Perhitungan Turner Rate}

Liquid loading adalah akumulasi cairan atau fluida di dalam lubang sumur. Hal ini dapat dipicu ketika laku alir di bawah rekomendasi aliran minimum. Fluida yang tertinggal membentuk kolom cairan yang stagnan sehingga memberikan penambahan tekanan hidrostatik. Untuk mengangkat fuida ke permukaan, dibutuhkan perhitungan kecepatan kritis, yaitu

$$
\begin{aligned}
& V_{t}=17.6 \frac{\sigma^{1 / 4}\left(\rho_{l}-\rho_{g}\right)^{1 / 4}}{\rho_{g}{ }^{1 / 2}} \mathrm{ft} / \mathrm{sec} \\
& V_{g}(\text { water })=5.62 \frac{(67-0.0031 p)^{\frac{1}{4}}}{(0.0031 p)^{\frac{1}{2}}} \text { and }
\end{aligned}
$$


$V_{g}($ condensate $)=4.02 \frac{(45-0.0031 p)^{1 / 4}}{(0.0031 p)^{1 / 2}}$

Sehingga didapatkan laju kritis gas dari perhitungan kecepatan kritis, yaitu

$Q_{g}=\frac{3.067 P V_{g} A}{(T+460) Z} M M s c f / D$

dimana $\quad A=\frac{(\pi) d_{t i}^{2}}{(T+460) Z} f t^{2}$

\section{Dimana}

$\mathrm{Q}_{\mathrm{g}}$ : Laju alir gas (MMscf/D)

$\mathrm{V}_{\mathrm{g}}$ : Kecepatan gas (ft/sec)

$\mathrm{T}$ : Suhu di permukaan $\left({ }^{\circ} \mathrm{F}\right)$

$\mathrm{P} \quad$ : Tekanan di permukaan (psi)

Z : Faktor kompresibilitas

A : Luas penampang tubing ()

$\mathrm{d}_{\mathrm{ti}}$ : ID tubing (in)

\section{Laju Alir Maksimum Pada Sumur Gas}

Erosi adalah berkurangnya suatu material oleh partikel padat atau tetesan cairan. Korosi merupakan bentuk lain dari degradasi material yang terjadi melalui reaksi kimiawi. Pada perhitungan laju maksimum agar tidak terjadi erosi, atau biasa disebut sebagai laju alir maksimum, dapat dihitung sebagai berikut :

$Q_{e}=1.86 \times 10^{5} A\left(\frac{p}{Z T \gamma_{g}}\right)^{0.5}$

Dimana

$\mathrm{Q}_{\mathrm{e}}$ : laju alir maksimum (Mscf)

A : luas area $\left(\mathrm{ft}^{2}\right)$

Z : kompresibilitas gas pada tekanan dan temperatur tertentu

$\mathrm{T}$ : temperatur (R)

$\mathrm{P}$ : tekanan (psia)

$\gamma_{\mathrm{g}}:$ Specific gravity gas

: densitas cairan gas-liquid

\section{E. Perhitungan Ukuran Choke}

Perhitungan choke yang digunakan mengikuti perhitungan laju alir multifasa menggunakan 
model Sachdeva (Guo, et all, 2007). Model ini menggunakan perhitungan total max flux melalui formula sebagai berikut :

$$
\begin{aligned}
& G_{2}=C_{D}\left\{288 g_{c} p_{1} \rho_{\mathrm{m} 2}^{2}\left[\frac{\left(1-x_{1}\right)(1-y)}{\rho_{L}}+\frac{x_{1} k}{k-1}\left(V_{G 1}-y V_{G 2}\right)\right]\right\}^{0.5} \\
& \frac{1}{\rho_{m 2}}=x_{1} V_{G 1} y^{1 / k}+\left(1-x_{1}\right) V_{L}
\end{aligned}
$$

Setelah mass flux didapatkan dari formula 7, maka mass flow rate dan ukuran choke dapat ditentukan dengan

$$
M_{2}=G_{2} A_{2}
$$

Dimana :

$\mathrm{G}_{2} \quad$ : Mass flux at downstream, $\mathrm{lbm} / \mathrm{ft}^{2} / \mathrm{s}$

$\mathrm{C}_{\mathrm{D}} \quad$ : discharge coefficient, 0.62-0.90

$\rho_{\mathrm{m} 2} \quad$ : densitas campuran, $\mathrm{lbm} / \mathrm{ft}^{3}$

$\rho_{\mathrm{m} 2} \quad$ : densitas liquid, $\mathrm{lbm} / \mathrm{ft}^{3}$

$\mathrm{A}_{2} \quad$ : choke-cross sectional area, $\mathrm{ft}^{2}$

$\mathrm{M}_{2} \quad$ : mass flow rate at downstream, $\mathrm{lbm} / \mathrm{s}$

\section{Metode Penelitian}

Metodologi dari penelitian yang akan dilakukan yaitu:

a. Studi Literatur

Penelitian ini diawalai dengan studi literatur. Studi literatur yang dilakukan yaitu terkait dengan persamaan empiris yang akan digunakan sebagai persamaan dasar pada penelitian ini dan batasan serta asumsi yang digunakan.

b. Pengumpulan data lapangan

Pada penelitian ini digunakan data - data lapangan dari sumur - sumur yang sudah dibor pada lapangan Anggrek. Data - data yang akan digunakan yaitu:

1) Data properti reservoir : porositas, permeabilitas, tekanan reservoir, dan lain-lain

2) Data properti fluida reservoir : PVT Fluida Sumur

3) Data kesediaan ukuran tubing produksi, yaitu ID 1.995, 2.441, 2.992, dan 3.958inch.

c. Simulasi Produksi Sumur Alpha Selama 9 Tahun

Simulasi ini dilakukan untuk mengetahui fenomena pada early, mid dan late production.

d. Perhitungan Laju Alir Minimum dan Maximum

Perhitungan dilakukan untuk melihat batas operasi sumur mempertimbangkan kejadian liquid loading dan erosi tubing.

e. Perbandingan hasil perhitungan dengan API-RP-14E 
f. Rekomendasi range operasi untuk 4 macam ukuran tubing

Dari hasil simulasi, akan ditentukan ukuran choke optimum untuk sumur tersebut agar dapat digunakan sejak masa awal produksi hingga sumur di-abandoned.

\section{Hasil Penelitian dan Pembahasan}

\section{A. Analisa Fluida dan Performa Sumur Lapangan Anggrek}

Lapangan Anggrek merupakan lapangan dengan tipe reservoir gas, tabel 1 menunjukan data reservoir. Data tersebut akan digunakan untuk membangun model tanki reservoir pada perangkat lunak yang digunakan. Sumur Alpha merupakan sumur vertikal yang akan menguras reservoir bagian Selatan Lapangan Anggrek. Pada penelitian ini, sumur Alpha divariasikan dengan 4 ukuran ID tubing produksi yaitu 1.995, 2.441, 2.992, dan 3.958inch.

Tabel 1. Data Reservoir Lapangan Anggrek

\begin{tabular}{|l|c|c|c|}
\hline Average Reservoir Pressure (psig) & 5800 & Wellbore radius (ft) & 0.354 \\
\hline Volumetric in place (Bscf) & 45 & Perforation interval (ft) & 60 \\
\hline Reservoir Temperature (F) & 210 & Porosity (fraction) & 0.25 \\
\hline Water-Gas ratio (stb/MMscf) & 0 & Connate water (fraction) & 0.2 \\
\hline Condensate Yield (stb/MMscf) & 15 & Mechanical skin & 5 \\
\hline Permeability (mD) & 50 & Drainage area (acres) & 90 \\
\hline Net Pay (ft) & 80 & Dietz Shape Factor & 31.6 \\
\hline
\end{tabular}
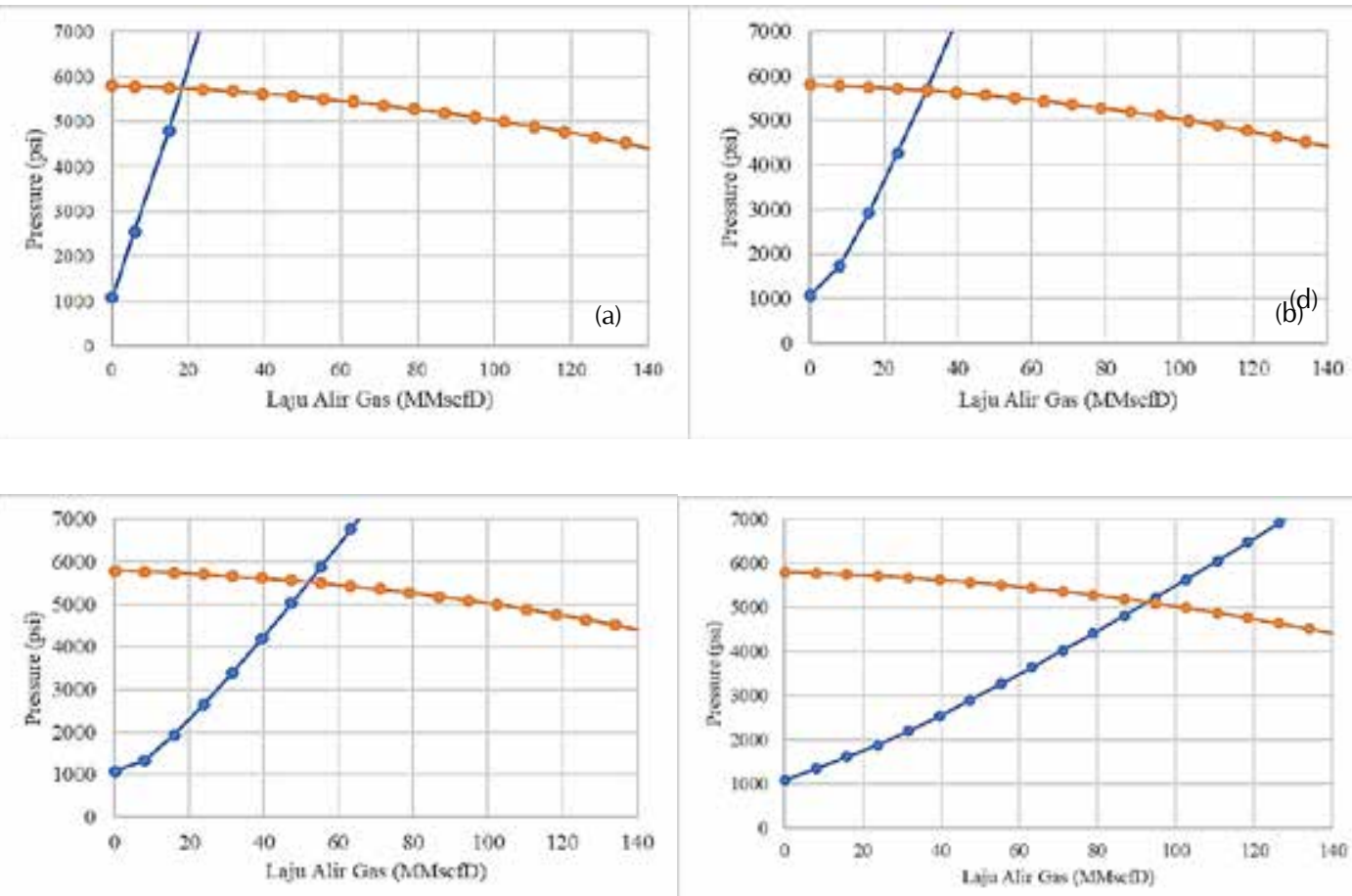

Gambar 1. Perpotongan Kurva Inflow dan Outflow Untuk Sumur dengan Ukuran Tubing ID 1.992” (a), $2.441 ”($ b), $2.992 \%$ (c), dan 3.958”(d) 
Dari hasil perhitungan pada Inflow Peformance Relationship (IPR), didapatkan bahwa Absolute Open Flow (AOF) pada sumur Alpha adalah sebesar 261.44MMscfD. Pada Gambar 1 diketahui perhitungan Vertical Lift Performace (VLP) memberikan hasil yang beragam, yaitu 18, 31, 52 dan 92MMscfD gas untuk ukuran ID tubing 1.995, 2.441, 2.992, dan 3.958inch.

\section{B. Perhitungan Laju Alir Minimum dan Maksimum Sumur Alpha}

Laju alir minimum diperlukan untuk mengantisipasi kejadian liquid loading. Turner rate merupakan salah satu persamaan untuk menghitung laju alir minimum agar gas dapat mengangkat fluida. Kecepatan gas minimum dapat diperkirakan dengan anggapan liquid berbentuk sheroidal dan selama pengangkatan tidak pecah. Laju alir maximum diperhitungkan dengan memperhatikan kejadian erosi pada tubing. Laju alir minimum dan maksimum mengacu pada formula 5 dan 7. Berikut hasil perhitungan laju alir minimum dan maksimum untuk 4 macam ukuran tubing:

Tabel 2. Perhitungan Laju Alir Minimum dan Maksimum Untuk 4 Macam Ukuran Tubing

\begin{tabular}{|l|c|c|}
\hline \multicolumn{1}{|c|}{ Ukuran Tubing } & $\begin{array}{c}\text { Turner Rate (Minimum) } \\
\text { MMscfD }\end{array}$ & $\begin{array}{c}\text { Erosion Rate (Maximum) } \\
\text { MMscfD }\end{array}$ \\
\hline ID 1.995" & 0.80 & 10.58 \\
\hline ID 2.441" & 1.21 & 16.24 \\
\hline ID 2.992" & 1.95 & 27.10 \\
\hline ID 3.958" & 4.18 & 68.02 \\
\hline
\end{tabular}

Tabel 2 merupakan hasil perhitungan laju alir minimum dan maksimum untuk keempat ukuran tubing. Dari perhitungan didapatkan bahwa semakin besar ukuran ID tubing maka laju alir minimum dan maksimum yang diperoleh juga meningkat. Hasil perhitungan ini akan mempengaruhi operasi bukaan choke pada sumur pada proses prediksi laju alir di tahap berikutnya.

\section{Perhitungan Laju Alir Maksimum Sesuai Rekomendasi API-RP-14E}

Lapangan Anggrek menerapkan rekomendasi API-RP-14E dalam menentukan laju alir maksimum. Laju alir maksimum dari API-RP-14E akan dibandingkan dengan laju alir maksimum yang didapatkan pada tabel 2. Berdasarkan tabel 3, nilai rekomendasi API-RP-14E lebih pesimis dibanding hasil perhitungan dengan erosional velocity. Pada API-RP-14E tidak mempertimbangkan faktor luas area yang merupakan geometri bidang alir. Dengan nilai batas yang baru, operator dapat menaikkan batas laju alir gas sebagai upaya optimasi produksi.

Berikut hasil perhitungan laju alir maksimum berdasarkan API-RP-14E (Eq. 1) : 
Tabel 3. Perbandingan Laju Alir Maksimum Dengan Erosional Velocity dan API-RP14E

\begin{tabular}{|l|c|c|}
\hline \multicolumn{1}{|c|}{ Ukuran Tubing } & $\begin{array}{c}\text { Erosion Rate (Maximum) } \\
\text { MMscfD }\end{array}$ & $\begin{array}{c}\text { Rekomendasi API-RP-14E } \\
\text { MMscfD }\end{array}$ \\
\hline ID 1.995" & 10.58 & 6.32 \\
\hline ID 2.441" & 16.24 & 9.48 \\
\hline ID 2.992" & 27.10 & 14.05 \\
\hline ID 3.958" & 68.02 & 29.79 \\
\hline
\end{tabular}

\section{Analisis Perolehan Produksi Sumur Alpha dengan Nilai Batas Operasi Baru}

Analisis produksi dilakukan dengan melihat performa produksi dan kumulatif yang dihasilkan selama 9 tahun. Prediksi laju produksi merupakan salah satu langkah penting dalam proses menentukan ukuran tubing. Selain recovery factor, hal lain yang perlu diperhatikan adalah waktu plateau produksi serta life-time dari sumur.

Batas operasi yang diperhitungkan menggunakan hasil pada tabel 2. Laju alir maksimum APIRP-14E tidak lagi digunakan dalam analisis ini. Berdasarkan simulasi, diketahui recovery factor untuk masing-masing ukuran tubing 1.995, 2.441, 2.992 dan 3.958" adalah 44\%, 62\%, 76\% dan $78 \%$. Pada tubing ID 1.995" dan 2.441" diobservasi sumur masih bias mengalirkan gas hingga 9 tahun produksi. Sedangkan pada ukuran tubing yang lebih besar, yaitu 2.992" dan 3.958", sumur tidak dapat lagi berproduksi setelah tahun ke 5 dan tahun ke-3.

Berdasarkan Gambar2 diketahui bahwa ID tubing 2.992 dan 3.958" mengalami penurunan produksi dan tidak dapat mempertahankan laju alir. Hal ini terjadi karena target maksimum laju alir cukup besar sehingga penurunan tekanan di awal produksi tidak dapat dihindari. Pada penelitian ini, batas operasi menjadi nilai mutlak yang harus dipenuhi. Apabila tidak mencapai kedua kondisi tersebut, maka secara otomatis sumur akan shut-in.

Ukuran tubing ID 1.995 dan 2.441" memberikan produksi yang lebih stabil karena penurunan tekanan dapat terjaga dengan baik. Kedua sumur tetap dapat memenuhi laju alir minimum, meski pada tahun ke-3 produksi keduanya tidak dapat mencapai laju produksi maksimum yang ditentukan. 


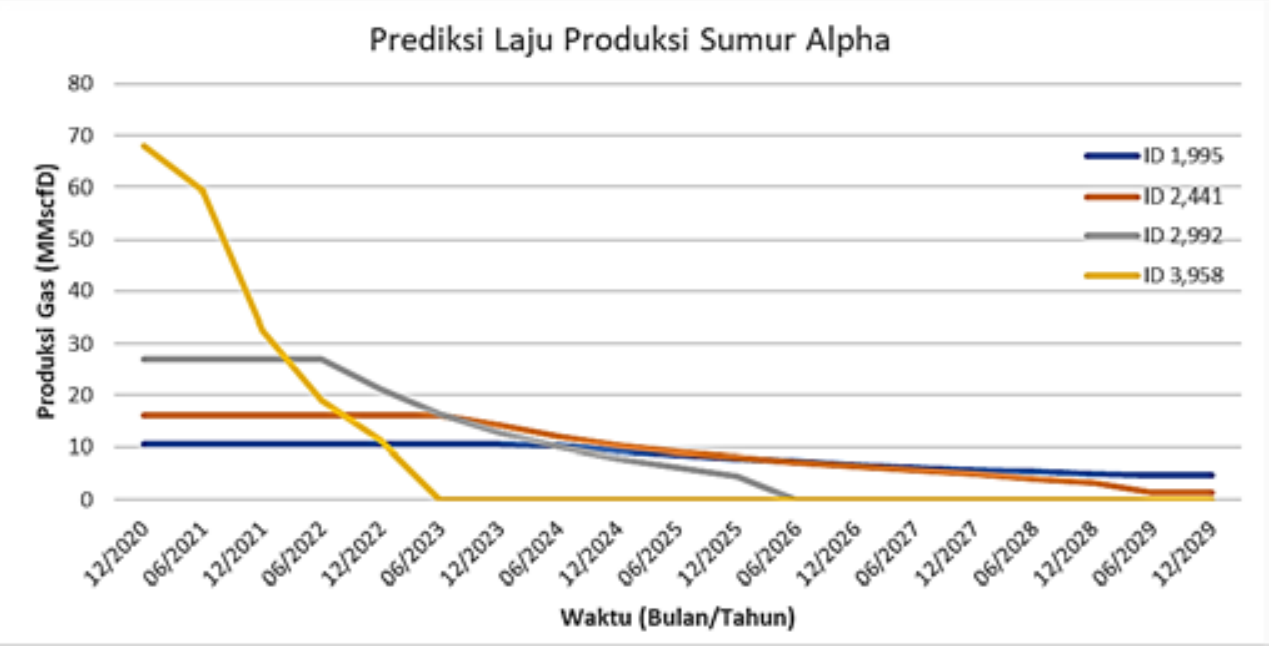

Gambar 2. Prediksi Laju Produksi Sumur Alpha

\section{E. Analisis Prediksi Kondisi Sumur}

Analisis prediksi kondisi sumur dilakukan dengan melihat superficial gas velocity dibandingkan dengan turner velocity. Apabila superficial gas velocity mulai berada di bawah turner, maka mulai terjadi timbunan liquid di dalam sumur. Jika hal ini berlangsung dalam jangka waktu yang lama, maka akumulasi cairan dapat menurunkan produktivitas sumur.

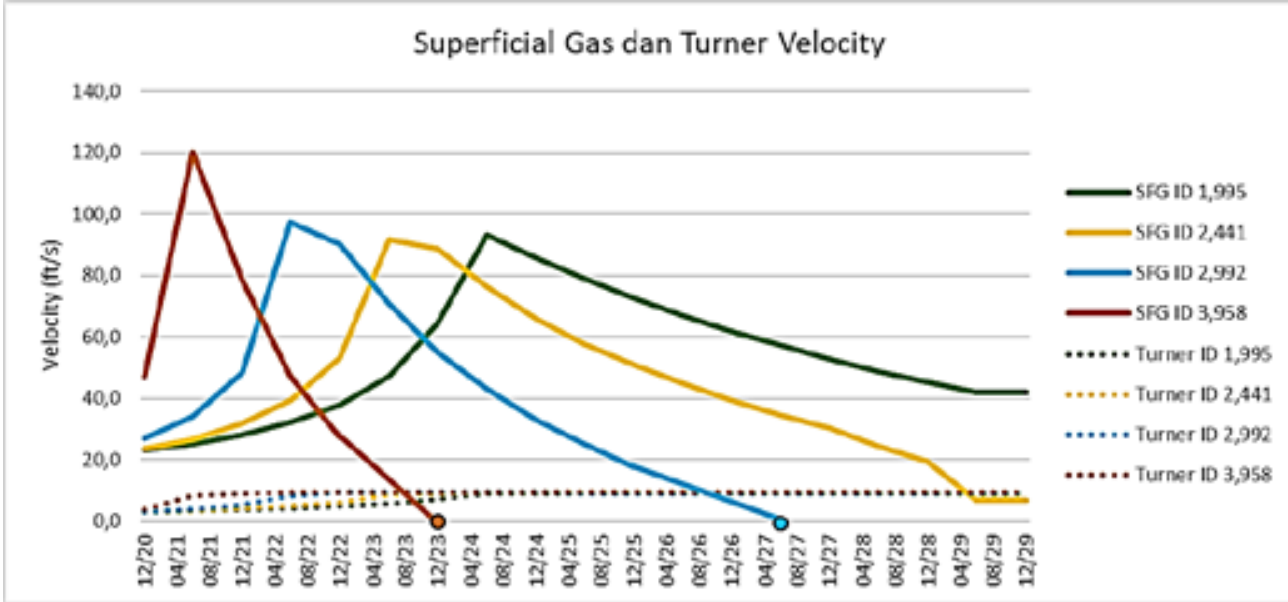

Gambar 3. Superficial Gas dan Turner Velocity Untuk Semua Ukuran Tubing

Berdasarkan Gambar 3 diobservasi bahwa sumur dengan tubing besar lebih cepat mengalami akumulasi cairan. Hal ini dapat dilihat dari titik perpotongan ketika nilai superficial gas velocity mulai berada di bawah turner rate. Waktu prediksi akumulasi cairan untuk masing-masing sumur adalah sebagai berikut 
Tabel 4. Prediksi Akumulasi Liquid Terjadi di Dalam Sumur

\begin{tabular}{|c|c|}
\hline $\begin{array}{c}\text { Ukuran } \\
\text { Tubing }\end{array}$ & Waktu Mulai Akumulasi \\
\hline ID 1.995" & Tidak terjadi akumulasi hingga 2029 \\
\hline ID 2.441" & April 2029 \\
\hline ID 2.992" & Agustus 2026 \\
\hline ID 3.958" & Juli 2023 \\
\hline
\end{tabular}

Berdasarkan tabel 4 diketahui bahwa tubing dengan ukuran lebih kecil dapat menunda akumulasi liquid, sehingga produksi lebih stabil. Kelebihan lainnya adalah perusahaan dapat mengurangi biaya operasi akibat masalah produksi liquid loading dan tidak perlu melakukan pengecilan/penggantian ukuran tubing ketika tekanan reservoir mulai turun. Hal ini dapat menjadi pertimbangan dalam menentukan ukuran tubing yang cocok untuk Sumur Alpha.

\section{F. Rekomendasi Bukaan Choke Untuk Sumur Alpha}

Pengaturan choke merupakan salah satu kegiatan yang dilakukan operator dalam proses produksi. Setiap dua hingga empat tahun, Lapangan Anggrek mengganti ukuran choke sebagai upaya optimasi sumur. Berikut ini merupakan rekomendasi bukaan choke berdasarkan laju alir minimum dan maksimum untuk masing-masing sumur.

Tabel 5. Rekomendasi Choke Sumur Alpha

\begin{tabular}{|l|c|c|c|c|}
\hline \multirow{2}{*}{ Tahun } & \multicolumn{4}{|c|}{ Rekomendasi Bukaan Choke } \\
\cline { 2 - 5 } & ID 1,995 & ID 2,441 & ID 2,992 & ID 3,958 \\
\hline $\mathbf{2 0 2 1 - 2 0 2 3}$ & $0,26-0,29$ & $0,32-0,39$ & $0,59-1,36$ & $0,95-1,04$ \\
\hline $\mathbf{2 0 2 4 - 2 0 2 6}$ & $0,30-0,35$ & $0,40-0,53$ & - & - \\
\hline $\mathbf{2 0 2 7 - 2 0 2 9}$ & $0,37-0,42$ & $0,59-0,71$ & - & - \\
\hline
\end{tabular}

Berdasarkan hasil simulasi didapatkan bahwa rekomendasi bukaan choke dapat diberikan untuk ukuran tubing 1.995 dan 2.441" selama 9 tahun produksi. Sedangkan untuk tubing yang lebih besar perlu dilakukan analisis lebih lanjut karena optimasi diperlukan untuk mengatasi liquid loading yang terjadi.

\section{Kesimpulan}

Berdasarkan studi yang telah dilakukan, diperoleh kesimpulan sebagai berikut :

1. Lapangan Anggrek memiliki potensi laju alir yang tinggi, yang dilihat dari nilai Absolute Open Flow (AOF) pada sumur Alpha sebesar 261.44MMscfD. Dalam penelitian ini menerapkan variasi ukuran tubing, sehingga memberikan perpotongan inflow dan outflow yang berbeda. Nilai dari perpotongan tersebut adalah 18, 31, 52 dan 92MMscfD gas untuk ukuran ID tubing 1.995, 2.441, 2.992, dan 3.958inch. 
2. Lapangan Anggrek menerapkan rekomendasi API-RP-14E dalam menentukan laju alir maksimum. Laju alir tersebut memiliki nilai di bawah erosional velocity. Laju alir minimum diperkenalkan pada rancangan batas operasi yang baru. Rentang operasi yang dihasilkan membuat batas laju alir maksimum naik,

3. Setiap ukuran ID tubing memberikan hasil batas laju alir minimum dan maksimum yang berbeda-beda. Semakin besar ukuran tubing, maka nilai batas yang direkomendasikan semakin meningkat. Hasil perhitungan produksi kumulatif dan recovery factor menunjukkan bahwa ukuran tubing yang besar memberikan perolehan yang lebih tinggi, meski life-time sumur cenderung pendek.

4. Kelebihan penggunaan tubing dengan ukuran lebih kecil adalah penundaan waktu terjadinya akumulasi liquid, sehingga produksi lebih stabil. Selain produksi, manajemen dapat mempertimbangkan biaya workover atau kemudahan operasi sumur dalam menentukan ukuran tubing.

5. Rekomendasi batas operasi dan bukaan choke telah diberikan untuk manajemen produksi sumur Alpha di lapangan Anggrek.

\section{Daftar Pustaka}

Febri, K.J., Kartoatmodjo \& Wati, K. F. (2017). Analisa Liquid loading Pada Sumur Gas FJRN-1. Buku-1 Seminar Nasional Cendekiawan ke 3 Tahun 2017

Guo Boyun, et all (2007) Petroleum Production Engineering, A Computer-Assisted Approach. Elsevier, Oxford

Pratiwi, A. R (2019). Penanggulangan Liquid loading Dengan Memperhatikan Pola Aliran Pada Lapangan KMB. Jakarta: FTKE-Usakti

R. G. Turner, M. G. (Nov. 1969). Analysis and Prediction of Minimum Low Rate for the Continuous Removal of Liquids from Gas Wells. Journal of Petroleum Technology, 1475-1482.

Sani, F.M, et al (2019). Review of the API RP 14E Eroisonal Velocity Equation : Origin, Applications, Misues and Limitations. Corrosion 2019. Nashville 